\title{
BARRIERS TO AND EXPECTATIONS OF Performing Physical Activity in Female SubJeCts With Type 2 DiabeTES.
}

\begin{abstract}
The aims of the study were to establish in a cohort of female patients with Type Diabetes the knowledge and perceptions of exercise, personal and environmental barriers to doing exercise and the outcome expectations of performing physical activity.

The sample consisted of 28 patients between the ages of 48 and 70 (mean $=60.2, S D=6.6$ ) years and 11 ethnic groups, attending the Mamelodi Hospital Diabetic Outpatient Clinic. The duration of the disease ranged from I to 22 years and $82 \%$ of the patients were using oral hypoglycaemic agents.

Demographic and qualitative data were captured by means of focus group interviews.

Demographic data were summarized with descriptive statistics. Qualitative data were analysed by means of welldescribed principles of qualitative data analyses. A percent agreement was performed and data were re-coded until the inter-rater reliability was $85 \%$.

All 28 subjects reported that they saw doing household chores and walking as ways of exercising. Sixty one percent of the subjects indicated relief from arthritis as a benefit of exercise. The main environmental barrier was the absence of a convenient venue (61\%). Tiredness (36\%) and arthritis (36\%) were the main personal barriers to doing exercise. All subjects indicated a better quality of life and improvement of functional capabilities as outcome expectations of taking part in an exercise program. Subjects had positive attitudes towards exercise, wanted to have control in the program and also expressed the need for social support.
\end{abstract}

KEY WORDS: TYPE 2 DIABETES MELLITUS, PERCEPTION OF EXERCISE, PERSONAL BARRIERS, ENVIRONMENTAL BARRIERS, OUTCOME EXPECTATIONS.

\section{INTRODUCTION}

Increasing trends in the prevalence of diabetes and in the societal costs of the complications of diabetes have focused attention on improving the quality of diabetes care (Songer 1995; King et al 1998). According to the World Health Organisation's (WHO) concept of rehabilitation, subjects should be encouraged to become increasingly self-responsible for their own active and productive life and thus for improving their own quality of life (WHO 1964). In a report by Eales and Stewart (2001), the following hypothesis was put forward: “... for subjects with chronic diseases to be considered successfully rehabilitated, they should accept responsibility for their own rehabilitation." They defined selfresponsibility as the moral duty of the patient to successfully execute the required health behaviour for improved health. Physical activity is recommended as part of the management regimen for subjects with Type 2 Diabetes Mellitus (Type 2 DM). The positive effects of regular physical activity on the prevention and control of Type 2 DM, hyperlipidaemia, insulin resistance, obesity and its overall impact on cardiovascular disease are reasons to stimulate subjects to perform regular exercise (Ligtenberg et al 1995). In addition sensible exercise can improve functional status, longevity and quality of life (Leon et al 1987).

However, it is known that long-term adherence to regular physical activity program for the elderly Type 2 DM patient is generally poor and that without supervision, compliance is low (Ligtenberg et al 1997).

Hays et al (1999) reported that factors which may influence the initiation and maintenance of exercise programs of Type 2 DM, are personal characteristics of the patient (personality, cognitiveand environmental factors) and environmental influences (social, cultural and economic factors).

Cognitive factors include knowledge, thoughts, attitudes and skills. In a study on the knowledge of, attitudes towards Type 2 DM and the level of physical activity of urban black female subjects, low educational levels, poor diabetes

CORRESPONDENCE TO:

AJ Van Rooijen

Department of Physiotherapy

University of Pretoria

P O Box 667,

Pretoria 0001

Tel: (012) 354-2018

Fax: (012) 354-1226

Email: tvrooije@medic.up.ac.za 
knowledge, low levels of physical activity and class I obesity status were reported (Van Rooijen et al 2001).

Tolerant cultural attitudes towards obesity within the black community may have contributed to this finding. The prevalence of obesity may contribute to discomfort which could lead to low long-term adherence to regular physical activity programs.

Swift et al (1995) reported that discomfort during exercise has been related to decreased participation in exercise in Type 2 DM subjects.

Barriers to the assumption of selfresponsibility are lack of knowledge, lack of sufficient interest in what is preventable and a culture of stressing individual rights which progressively erodes the idea of individual responsibility (Eales and Stewart 2001).

Behavioural change in Type 2 DM subjects will depend on patients' beliefs regarding the outcome of performing certain behaviours and the importance he/she attaches to the outcome. Little is known about the health beliefs and outcome expectations regarding physical activity, with specific reference to the culture of urban black female subjects with Type 2 DM. Environmental barriers to physical activity in this sample are also unknown.
The aims of this study were to establish participants' knowledge and perceptions of exercise, the kind of exercises they wanted to do, the personal and environmental barriers to doing exercise and the outcome expectations of performing physical activity in this sample of subjects.

(See Figure 1)

\section{METHOD}

Ethical clearance was obtained from the Ethics committee of the Pretoria Academic Hospital) Number 116/99). The superintendent and matron of the Mamelodi Hospital also consented to the study.

\section{Subjects}

The convenience, purposive sample consisted of a subset of a larger study that had been conducted one year prior to this study (Van Rooijen et al 2001). Twenty-eight black women with Type 2 DM, between the ages of 48 and 70 , who participated in the previous study, were contacted by telephone. All the women were attending the Hospital Diabetic Outpatient Clinic in Mamelodi. Subjects from the same gender and socioeconomic background were used to ensure homogeneity of the group (Côte-Arsenault and Morrison-Beedy
1999). The only exclusion criterion was disinterest in doing exercise. Four to ten subjects were recruited for each focus group to avoid no shows, an unproductive discussion of too small a group of subjects or the danger that smaller discussions may start in a group that was too large (Maillet NA et al 1996). Subjects were compensated for their transport costs and were served refreshments and received a small gift after the focus group. The data capturing commenced on 22 March 2001 and was completed on 10 April 2001.

\section{Setting}

Focus groups were held in a relaxed, informal setting at the Mamelodi Day Hospital. This hospital was accessible, convenient, non-threatening and acceptable to the participants. As a result it allowed for and encouraged open discussion. Seating facilities were adequate ensuring maximum opportunity for eye contact with both the facilitator and other group members. Two audiotape recorders were placed centrally to ensure good quality recording.

\section{Instrumentation}

Demographic and qualitative data were captured. The phenomenological approach by means of focus group inter-

Figure 1: Factors infuencing the initiation and maintenance of physical activity in black women with Type 2 Diabetes Mellitus.

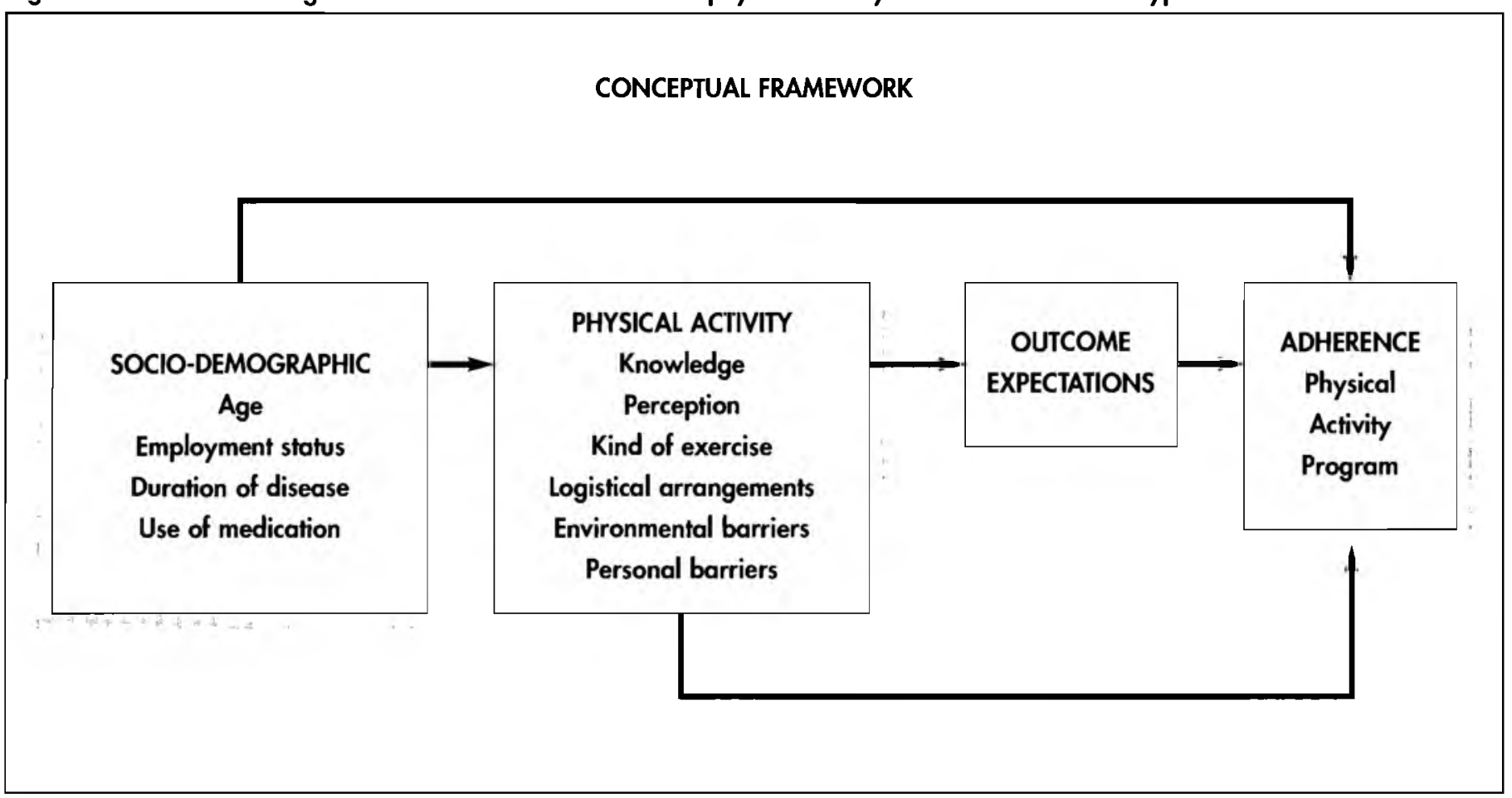


views was used to provide an understanding of the social and behavioural attitudes of individuals (Maillet et al 1996). Structured questions were used, with open questions by the facilitator around a topic when indicated. The focus group technique was a cost-effective method to obtain in-depth information from a homogeneous group that may be useful in developing intervention programs for risk reduction of chronic diseases (Quatromoni et al 1994). It was also an effective method of obtaining data from subjects with a low educational level (Betts et al 1996). An exploratory approach was followed to understand the needs, language and beliefs of the sample and to gain insight into the health beliefs and outcome expectations regarding physical activity (CôteArsenault and Morrison-Beedy 1999). The open response format of the focus group provided an opportunity to obtain large and rich amounts of data in participants' own words. However, generalisa- tion of the results is difficult, because small numbers of subjects were interviewed and were not randomly selected.

A skilled and expert group facilitator, who was knowledgeable about Type 2 DM and familiar with group dynamics was selected and trained. She also translated the questions into Tswana. A fieldworker was trained to take detailed field notes and record behavioural data. The research team met beforehand to prepare the venue, test the equipment and to clarify each member's role. The focus groups were conducted in Tswana.

The first question was simple and neutral to allow the participants to feel comfortable and the get to know a little bit about the other participants around the table and to establish rapport. Questions were addressed to the group as a whole, taking care not to single out individual participants. The questions logically progressed from the general to the specific and were asked in four main categories: (See Table 1)

Table 1: Questions used for discussion during the focus groups in English and Tswana.

Knowledge and perceptions / Kitso
Do you want to do exercise?
A o blatla go ikwetlisa?
What do you perceive exercise to be?
Go ya ka wena, o akanya gore go ikwetlisa ke eng?
Why do you think it is important to exercise?
O akanya gore bothlhokwa ba go ikwetlisa ke eng?

Logistical / Dithomamiso

What sort of exercise do you want to do?

Ke mokgwa ofe o batlang go ikwetlisa ka one?

Do you want to exercise on you own or in a group?

A o batla go ikwetlisa oleng mong kgotsa le batho ba bang?

What is the best time of day for you to exercise and where do you want to exercise?

Ke nako efe va letsatsi e e gosiametseng go ikwetlisa?

Where do you want to exercise?

O batla go ikwetlisa felo gofe?

Environmental and personal barriers / Dikgoreletsi
What will keep you from exercising?
Ke eng se seka go thibelang go ikwetlisa?
What would make you leave an exercise program?
Ke eng se seka dirang go re o tlogele go ikwetlisa?
What would make you stay in an exercise program?
Ke eng se seka dirang gore o kgothalle go ikwetlisa?

Expected outcomes / Ditlamorago

How do you think you can benefit from doing exercise?

O akanya gore ditlamorago tse mosola tsa go ikwetlisa mo go wena e ka ba eng?

How do you want to feel if you exercise?

Maikutlo a gago, o batla a bajwang morago ga go ikwetlisa?

\section{Process}

The subjects reported at 09:00 on the day of their appointment to the research venue. Each subject was welcomed and introduced to the research team. lnformed consent was obtained from each patient after the aims, procedures and possible benefits of the study were explained to them. Subjects had the opportunity to ask questions before the consent form was signed. Each subject received a signed copy of her own consent form.

The participating subjects were given nametags to provide a basis for building greater rapport between the facilitator and the participants. It also enabled the facilitator to direct questions at a group member by name and achieve simultaneous eye contact. In this way greater identity and cohesiveness between the group members was developed (Richter 200I).

A short demographic questionnaire was completed consisting of age, ethnic group, employment status, duration of disease and use of medication.

The facilitator welcomed the participants and introduced herself and the fieldworker.

Subjects were asked to introduce themselves as an icebreaker. The facilitator explained the purpose of and the course of the focus group discussion. The importance of each participant's contribution was stressed. The rules for the group discussion were given and the role of the fieldworker was explained.

The use of the two audio tape recorders was explained and subjects were assured that the recordings would only be listened to or looked at by the researcher and that the participants would stay anonymous.

A definition of physical activity and exercise was given.

The research questions were then put forward and participants were asked to participate in the discussion. The facilitator addressed questions to the group as a whole and no subject was singled out. Asking inquisitive questions, using summaries and reflection, without interfering with the dialogue of the interview, facilitated active participation of all group members.

The fieldworker documented the order in which subjects spoke to aid 
voice recognition of the recording. Nonverbal behaviour such as eye contact, posture, gestures between group members was also documented.

After the focus group, subjects were thanked and acknowledged for the useful information. Teas and eats were served. Debriefing with the research team was done to discuss important information during the post-group discussions.

Focus groups with participants were conducted until a clear pattern emerged and subsequent focus groups repeated information (McDougall 1999).

\section{Possible sources of bias}

Multiple focus groups were held to decrease threats to external validity. Training of the facilitator in the manner of questioning, reduced bias in data collection. Aggressive and dominant subjects were prevented from taking over the discussion.

\section{STATISTICAL AND DATA ANALYSIS}

Demographic data were entered into a file on the Statistics - program on the computer, screened for missing values. Data were analysed using Statistics (B) software. Data were summarised with descriptive statistics: mean, SD, median, range, frequency and percentage.

Transcripts were made from the audio tape recordings in Tswana. A trained multilingual nurse translated the transcriptions and field notes into English.

Transcripts were read through several times by the researcher to get a sense of common themes that were relevant to the research question (Strauss and Corbin 1990). Line-by-line analysis was done to generate categories. Notes were made, throughout the reading on general themes in the transcripts. This enabled the researcher to become more fully aware of the participants' frames of reference. Open coding was done by reading through the transcripts again and by making as many headings as necessary to describe all aspects of the content.

Grouping them together into broader categories reduced the numbers of categories. Repetitious and very similar headings were removed to compile a final list of categories.

Asking an independent qualitative researcher to generate categories with-

Table 2: Demographic data.

\begin{tabular}{|l|c|c|c|}
\hline \multicolumn{2}{|c|}{ Demographics } & N & $\%$ \\
\hline Ethnic group & North Sotho & 5 & 18 \\
& Ndebele & 4 & 14 \\
& Zulu & 5 & 18 \\
& Mopaedi & 3 & 11 \\
& Tswana & 5 & 18 \\
& Tsonga & 2 & 7 \\
Employment & Other & 4 & 14 \\
status & Full day work & 1 & 4 \\
& Part-time work & 1 & 4 \\
\hline Pension & Unemployed & 26 & 92 \\
\hline Duration of & Yes & 14 & 50 \\
disease (years) & No & 14 & 50 \\
& $1-4$ & 8 & 29 \\
& $5-7$ & 7 & 25 \\
& $8-10$ & 4 & 14 \\
& $11-13$ & 4 & 14 \\
& $17-19$ & 2 & 7 \\
\hline Medication & $20-22$ & 3 & 11 \\
\hline & Insulin injections & 5 & 18 \\
& Tablets & 23 & 82 \\
\hline
\end{tabular}

out seeing the researcher's list enhanced the validity of the categorising method. It also reduced researcher bias. Lists were compared, discussed and adjustments were made.

The degree to which the chosen categories covered all aspects of the interviews were evaluated and adjusted. Each transcript was then worked through with the list of categories and sub-headings and coded accordingly. Ten percent of the data was given to an independent researcher for a reliability check at the researcher's coding scheme. A percent agreement was performed between the independent researchers' and the researcher's codes. The use of the codes that were unclear was identified. Decision rules were created to clarify the use of the codes that were unclear. Another small subset was then re-coded until the inter-rater reliability was $85 \%$. This process ensured that the researcher's codes and categories were understandable, exhaustive, mutually exclusive and independent. Each coded section of the interview was then cut out of the transcript and all items of each code were grouped.

The cut out sections was pasted onto sheets, headed-up with the appropriate headings and sub-headings. All sections were filed together for direct reference when writing up the findings. Copies of the complete interviews and the audio tape recordings were kept in a safe place.

\section{TRUSTWORTHINESS OF THE DATA}

Credibility of the data was obtained by the fact that the researcher did not facilitate the focus groups. In this way the researcher could not have influenced the subjects with her knowledge in the field (reflexivity). Field notes were kept throughout the research process. The researcher discussed the research process and findings with an impartial colleague who has experience with qualitative research (triangulation).

The transferability of the data was improved by providing a dense description of the background information on the subjects. The description of the exact methods of data gathering, analysis and interpretation contributed to the auditability of the study. A colleague, who was not involved in any other aspects of the study, but who is familiar with the process of category generation was asked to read through two transcripts and to identify a category system. 
It was then discussed with and compared to the researcher's category system (confirmability).

\section{RESULTS}

The results are presented in the following order:

Demographic, focus groups and integrated results.

\section{Demographical data}

The demographics of this sample by ethnicity, employment status, receiving pension, duration of diabetes and type of medicine used are provided in Table 2.

The mean age of the sample group was 60,18 years $(6.55)$. Ages ranged from 48 to 70 years, with a median of 60.5. Other ethnic groups included single Coloured, Mopele, Moswazi, and Motebele subjects. All of the mentioned ethnic groups could understand and speak Tswana.

\section{Focus group data}

The subjects were relaxed during the focus groups. They laughed easily and used a lot of hand signs and body movements during talking. Three subjects got up and demonstrated how they would do certain household tasks.

The following categories were derived from the data:

- Perception of exercise

- Personal barriers

- Environmental barriers and logistical arrangements

- Outcome expectations of an exercise program

- Adherence to an exercise programme

\section{Perception of exercise}

All 28 subjects reported that they were doing household chores and that they saw that as a way of exercising. Household chores consisted of doing laundry, going to the shops, cooking, washing, gardening, cleaning the home, carrying a baby on the back.

Walking as a way of exercising was mentioned 40 times during the 5 focus groups, however the intensity of walking ranged from walking far distances to walking as a possible way to exercise.

"I always walk distances and I do household chores and that way I exercise"

Table 3: Summary of identified benefits of exercise.

\begin{tabular}{|l|c|c|c|}
\hline \multicolumn{1}{|c|}{ Identified Benefit } & $\mathbf{N}$ & $\begin{array}{c}\text { Frequency } \\
\text { of response }\end{array}$ & $\begin{array}{c}\text { Percentage } \\
\%\end{array}$ \\
\hline Weight loss & 28 & 9 & 32 \\
Belter circulation & 28 & 6 & 21 \\
Helps for Arthritis & 28 & 17 & 61 \\
Body stays healthy & 28 & 6 & 21 \\
Relief of constipation & 28 & 1 & 4 \\
Improved sleeping & 28 & 1 & 4 \\
Improve blood sugar & 28 & 10 & 36 \\
Feel better & 28 & 7 & 25 \\
Relaxes them & 28 & 5 & 18 \\
\hline
\end{tabular}

"To me exercise means going to the garden to water my crops and harvest and then go home. When I arrive home, I clean the yard and then I sit down. In the afternoons I take a walk around my yard."

Subjects also expressed the following benefits of exercise: (See Table 3)

The following statement by one of the subjects stressed the psychological benefit of exercise:

"Sometimes when you wake up, you are not feeling well, sometimes you meditate about your problems, but when you exercise, you don't concentrate on those things and you become happy and you believe that everything will be fine."

\section{Personal barriers}

Subjects expressed psychological and physiological barriers to exercise. Psychological barriers were stress-related, not feeling well and forgetfulness.

"When you arrive home an you feel bad and you meditate on other things in life and your sugar level goes up...."

"I am meditating a lot about my problems and you know diabetes makes you forgetful"
"I am always on and off and I can't be active"

Several subjects also mentioned that their bodies were "already sick with diabetes".

Two subjects also felt that they had lost too much weight and 2 subjects indicated that they were too lazy to exercise. "I know that we are supposed to exercise, its just that we are so lazy to exercise" Subjects also indicated that they did not know what other exercises to do apart from walking and doing household chores and that they were not used to make choices regarding health care for themselves. One subject was of the opinion that people would think that she is insane if she exercised.

Two other subjects indicated that they did not want to lift their legs in lying, did not like running around and that they did not want to wear gym clothes. One subject felt that diabetes patients were not treated well at the Diabetes clinic and had to wait a long time to see the doctor, only not to be informed about their illness.

I"Sometimes you come in very tired and the doctor do not tell you anything...."

Physiological barriers to exercise are presented in Table 4.

Table 4: Summary of physiological barriers to exercise.

\begin{tabular}{|l|c|c|c|}
\hline $\begin{array}{c}\text { Identified } \\
\text { Physiological barrier }\end{array}$ & N & $\begin{array}{c}\text { Frequency } \\
\text { of response }\end{array}$ & $\begin{array}{c}\text { Percentage } \\
\%\end{array}$ \\
\hline Tiredness & 28 & 10 & 36 \\
Arthritis & 28 & 10 & 36 \\
Foot problems & 28 & 6 & 21 \\
Sore body & 28 & 4 & 14 \\
Respiratory problems & 28 & 3 & 11 \\
Other illnesses & 28 & 2 & 7 \\
\hline
\end{tabular}


Environmental barriers and logistical arrangements

The lack of a convenient venue to do exercise in was the main environmental barrier. Sixty-one percent of the subjects staying in different areas of the Mamelodi community indicated that the Mamelodi Day Hospital was too far to travel to on a regular basis. The subjects wanted a venue for diabetics only, because they felt that there would not be harmony if other people joined the group. The venue would have to be easily accessible due to the cost of transport. They did not want to do exercises on Thursdays, because it was the day when they go to church. The majority of the subjects also felt that the exercise classes should not be on a clinic day, due to the long waiting periods at the clinic.

One subject mentioned that the community members were impatient with the older people walking slowly.

\section{Outcome expectations}

Subjects had the following outcome expectations from an exercise program:

- Better health

"When you wake up, you should not feel tired and heavy; your body must be flexible"

- Improved quality of life

"We want to have a good life, there is nothing that can conquer a good life"

- Education

"Apart from exercises, we need some advises one how to handle the illness and how to deal with problems like stress"

- Weight loss

" It will help me reduce my appetite, because people with diabetes eat a lot"

- Stress relieve

"I want to feel relaxed and peaceful....now after we have exercised we will be laughing and we will feel very good afterwards"

- Better control of the $\mathrm{HbA}_{\mathrm{lc}}$

"I will remember that my sugar level is high"

- Group support

"Advises that we can give each other, as we meet and chat"

- Fun

"Attending exercises to be fun, so that we always want to come back again next Tuesday and that you will be looking forward to that day"

Table 5: Adherence to an exercise program.

\begin{tabular}{|l|l|}
\hline \multicolumn{1}{|c|}{ Positive influences } & \multicolumn{1}{c|}{ Negative influences } \\
\hline - A program suitable for their & - Visitors \\
- physical abilities & - Illness \\
- Good working relationship & - "Not feeling well" \\
- Group support & - Social responsibilities \\
- Only diabetes patients & - Household chores \\
- Agreement with program & - Cost of transport \\
- Patience of presenters of program & - Family affairs \\
- Improvement in health & - Difficulties at home \\
& - Tiredness \\
& - Laziness \\
\hline
\end{tabular}

\section{Adherence to the program}

The subjects were of the opinion that the following factors would influence their adherence to an exercise program: (See Table 5)

Subjects felt that they were compelled to try the exercises if they were serious about their health.

"We won't stop as soon as we have started, it is not possible, we follow what we have been told...but if you are disrespectful you will not come to exercise"

\section{DISCUSSION}

Taking the time to listen to patients' views about health care and how they experience it is instrumental to developing programs that are acceptable to the communities. Satisfactory health care involves not merely improvement from bodily symptoms, but the social and psychological reintegration of the patient and the community (HammondTook 1989).

Qualitative research methodology was used to improve the understanding of patients' perception of exercise, personal and environmental barriers to doing exercise and outcome expectations of an exercise program. The sample consisted of mainly older female Type 2 Diabetes Mellitus patients, attending the Mamelodi Diabetes Clinic. The sample group consisted of 11 ethnic groups of whom $92 \%$ were unemployed. The duration of the disease ranged from 1 to 22 years and $82 \%$ of the patients were using oral hypoglycemic agents. All 28 subjects reported doing household chores and walking as ways to exercising.

The most important findings of this study were that the participants knew the physiological and psychological bene- fits of exercise and that they should take responsibility to exercise if they were serious about their health.

\section{Environmental barriers and logistical arrangements}

The lack of a convenient venue to do exercise in was the main environmental barrier mentioned by the majority of the subjects. The ideal self-management intervention must be relatively low cost and cost-effective and a large percentage of the relevant population must be willing and able to participate (Norris SL et al 2001).

Utilization of community resources is important in this aspect. In this way the issues of social support and spirituality in patients' self-care will be addressed, but it would also serve as a means to educate patients, their families and the community about improving diabetes management (Samuel-Hodge et al 2000).

Older adults with diabetes are often incorrectly stereotyped as being slow and unmotivated in managing their diabetes as one of the subjects in the current study had pointed out (Mooradian AD et al 1999). Diabetic complications often interfere with sleep and increase the risks of falls. Fear of falling will force patients to reduce their mobility. It is therefore crucial that the functional capabilities as well as the gait and balance of patients should be assessed. An exercise program may develop stronger muscles and bones and reduce the risks of falls and fractures. In this way the sense of well-being and agility may be improved.

\section{Perception of exercise}

In this study the perception of exercise by the sample corresponded well with 
the types of physical activity for older people as documented by the World Health Organization, with all 28 subjects reporting that they were doing household chores namely gardening, housework and walking (WHO 1999). Kriska (2000) also stated that housework and family care taking appear to take a substantial portion of the total energy expenditure of an average day. However, it was shown in a previous study in a similar sample of Type 2 Diabetes patients in Mamelodi that the more active subjects were doing household and leisure time activities, but not on a regular basis (Van Rooijen et al 2001). Although exercise does not need to be strenuous or prolonged it should at least include 30 minutes of daily leisure activities such as walking or gardening, which are readily attainable by this sample group (Wannamethee $S$ 2001, Blair SN and Jackson AS 2001).

\section{Personal barriers}

Personal barriers are patients' perceptions of their illness, including diseaserelated beliefs, emotions, knowledge and experiences. Subjects expressed lack of knowledge, as well as psychological and physiological barriers to exercise. These findings correlate with a recent study by Samuel-Hodge (2000) and associates, on the influences on day-to-day selfmanagement of Type 2 Diabetes among African-American women. Being tired can be attributed to multiple causes including general life stress, physical exertion and diabetes. Diabetes-related tiredness may be caused by the psychological impact of the disease on the patient in terms of fear and worry about the disease. Patients aptly expressed this in the following way: "I am meditating a lot about my problems" and "I am already sick with diabetes". The physiological barriers can be attributed to a sedentary lifestyle and complications of Type 2 Diabetes, such as hypertension and macro-vascular disease (Songer 1995).

The lack of diabetes knowledge also contributes to the health-related stress: "Sometimes you come in very tired and the doctor do not tell you anything." Subjects also indicated that they did not know what other exercises to do apart from walking and doing household chores and that they were not used to make choices regarding health care for themselves. In a recent focus group study on African-American Women's Exercise Barriers the following was stated:

"We as Black women have not been taught about exercise, where this is like a luxury thing. I was not taught the value of exercising or eating right until I got to be an adult..." (Crosson et al 2000). An effective diabetes management program may address these barriers. It should respect an individual's habits, routines and lifestyle and incorporate social support (Norris SL et al 2001).

\section{Outcome expectations of an exercise program}

Two major expectations came to the fore in the responses of the subjects:

Improvement of functional capabilities:

- Physical: "When you wake up, you should not feel tired and heavy; your body must be flexible" and "it will help me reduce my appetite, because people with diabetes eat a lot"

- Cognitive: "Apart from exercises, we need some advises one how to handle the illness and how to deal with problems like stress" and "I will remember that my sugar level is high"

- Social: "Advises that we can give each other, as we meet and chat" and "Attending exercises to be fun, so that we always want to come back again next Tuesday and that you will be looking forward to that day"

Improvement of well-being:

- Perception of health: "I want to feel relaxed and peaceful ... now after we have exercised we will be laughing and we will feel very good afterwards"

- Emotional function: "We want to have a good life, there is nothing that can conquer a good life".

Adults who feel good about their emotion al functioning may exercise and be more active (Spirduso WW and Cronin Dl, 2001).

\section{Adherence to an exercise program}

Researchers have been unable to conclusively distinguish strong characteristics of exercise adherence and exercise non-adherence (Kerner MS et al 2001, Oldridge et al 1990). The following categories could however be identified:
- Attitude towards exercise

- Support by significant other persons

- Perception of control

- Motivation

The responses of the subjects in the present study have shown that the same categories will also influence their adherence to exercise. Subjects had a positive attitude towards exercise, because they had a good perception of exercise and knew what the benefits of exercise were. The need for support by significant other persons was expressed by their need for good working relationships, patience by the presenters of the exercise program and group support. The respondents wanted to have control in the program by stating that it should be suitable for their physical abilities, that they should agree with the program and that it should be for diabetic patients only. The negative influences on adherence to exercise mentioned by the subjects may be an indication of poor motivation to do exercise. For a diabetes self-management program to succeed, patients must adhere to it and be compliant with behaviour changes. However, the decision not to comply with such a program may be quite reasonable, particularly if the program does not meet patient expectations, is inconvenient or conflicts with other priorities, such as social responsibilities, household chores and family affairs.

Oldridge and Spencer (1985) have shown that the lack of support from the spouse and inconvenience was associated with the highest risk for dropout from an exercise program.

\section{CONCLUSION}

It can be concluded from the results of this qualitative study that the subjects had a good perception of exercise, knew the benefits of exercise and wanted to have a higher quality of life by means of feeling better and function better on a daily basis. However personal and environmental barriers may contribute to a risk for dropout from an exercise program if they are not addressed. Patient beliefs, attitudes and behaviours are influenced by cultural and socio-economic factors and are important. The relationship of culture to health beliefs, attitudes and behaviour is especially 
Figure 2: Factors infuencing the initiation and maintenance of physical activity in black women with Type 2 Diabetes Mellitus.

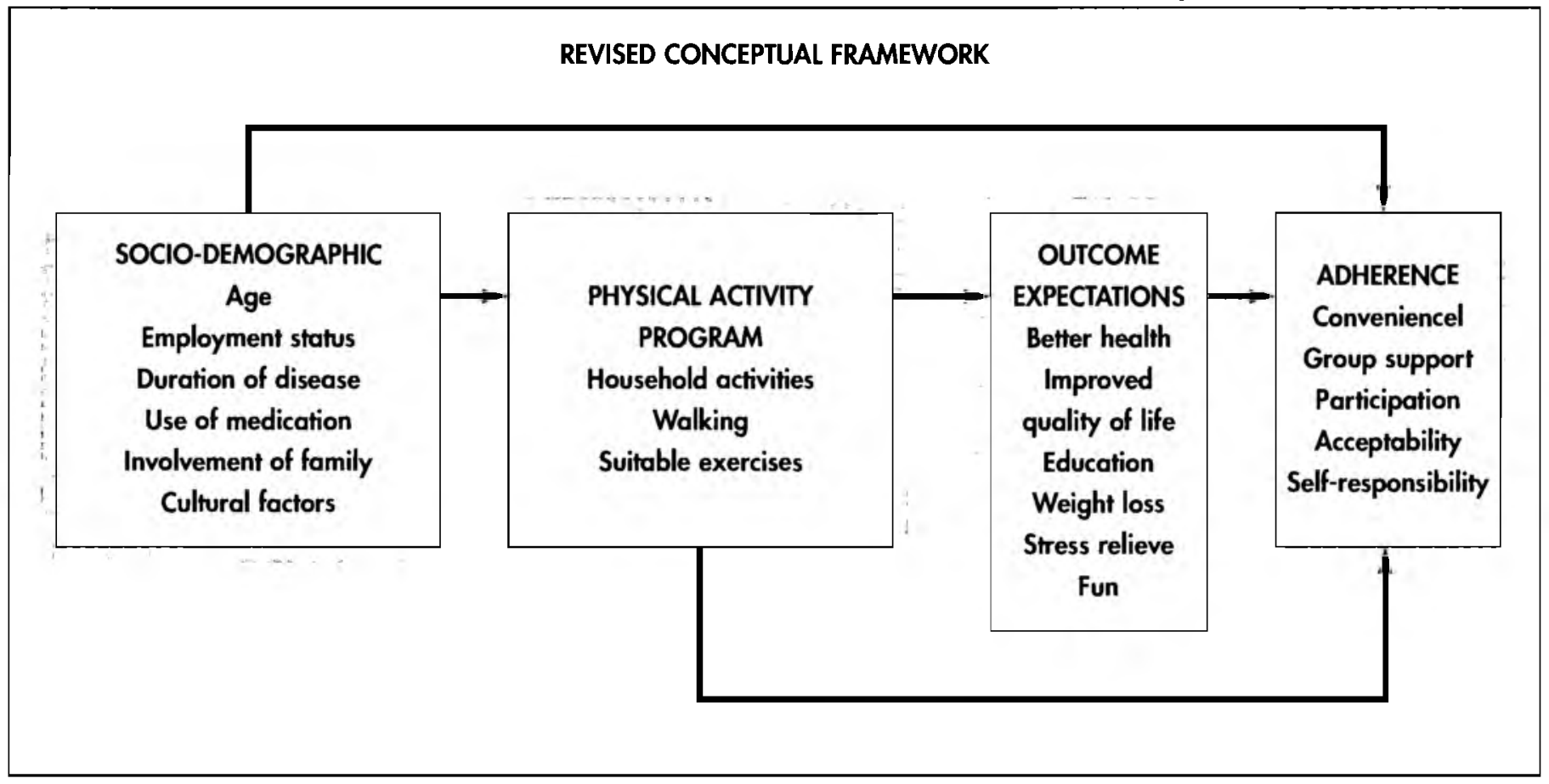

important in the treatment of diabetes, which usually includes changing patterns of eating, physical activity and other culturally embedded behaviours. If a diabetes exercise program is to be effective, it must be sensitive and relevant to the culture of the people expected to carry it out, be convenient and involve spouses and family members.

It is clear from the results that a coordinated team approach is needed to address these outcome expectations. Clark et al (2001) also endorses such an approach in a recent publication on changing the way diabetes is treated.

The conceptual framework is therefore revised to the following:

\section{ACKNOWLEDGMENTS}

The South African Society of Physiotherapy's Research Fund funded this ongoing research on the physical activity of urban black female patients with Type 2 Diabetes.

\section{REFERENCES}

Betts NM, Baranowski T, Hoerr SL 1996 Recommendations for planning and reporting focus group research. Journal of Nutrition Education 28: 279-281

Blair SN, Jackson AS 2001 Physical fitness and activity as separate heart disease risk factors: a meta-analysis. Medicine and Science in Sports and Medicine 33:754-761
Burnard P 1991 A method of analysing interview transcripts in qualitative research. Nursing Education Today 11: 461-466

Butchart A 1997 The Bantu Clinic: a genealogy of the African patient as object and effec1 of South African Clinical Medicine, 1930-1990. Cultural Medicine Psychiatry 21(4): 405-47

Clark CM, Fradkin JE, Hiss RG, Lorenz RA, Vinicor F, Warren-Boulton E 2001 The National Diabetes Education Program, changing the way diabetes is treated. Diabetes Care 24(4) 617

Côte-Arsenault D, Morrison-Beedy D 1999 Practical advice for planning and conduction focus groups. Nursing Research 48:280-283

Crosson P, Zhu W, Timm G 2000 African American Women's Exercise Barriers: a focus group study. Research Quarterly for Exercise and Sport 7।(1): pA-100

Department of Health 1997 Policy Guidelines on the prevention of physical inactivity in older persons at primary level - Draft 1

Eales CJ, Stewart AV 2001 Health and responsibility self-efficacy, self-care and self-responsibility. South African Journal of Physiotherapy 57: 20-25

Fitzgerald JT, Gruppen LD, Anderson RM, Funnell MM, Scott S., Grunberger G, Aman LC 2000 The Influence of Treatment modality and Ethnicity on Attitudes in Type 2 Diabetes. Diabetes Care 23(3): 313

Glasgow RE, Strycker LA, Hampson SE, Ruggiero 1997 Personal model beliefs and social-environmental barriers related to diabetes self-management. Diabetes Care 20: 556-561
Hammond-Took D 1989 Rituals and Medicines: Indigenous Healing in South Africa. AD Donker Publisher, Johannesburg: 17-163

Hays LM, Clark DO 1999 Correlates of physical activity in a sample of older adults with Type 2 Diabetes. Diabetes Care 22: 706-712

Kerner MS, Grossman AH 2001 Scale construction for measuring attitude, beliefs, perception of control and intention to exercise. Journal of Sports Medicine and Physical Fitness 41: 124-131

Kimchi J, Polovka B, Stevenson JS 1991 Triangulation: operational definitions. Nursing Research 40: 364-366

Krefting L 1991 Rigor in qualitative research: the assessment of trustworthiness. The American Journal of Occupational Therapy 45: 214-222

Leon AS, Connett J, Jacobs DR, Rauramaa R 1987 Leisure-time physical activity levels and risk of coronary heart disease and death Journal of the American Medical Association 258: 2388-2395

King H, Aubert RE, Herman WH 1998 Global burden of diabetes, 1995-2025: prevalence, numerical estimates and projections. Diabetes Care 25: 26-35

Kriska A 2000 Ethnic and cultural issues in assessing physical activity Research Quarterly for Exercise and Sport 71: 47-59

Ligtenberg PC, Hoekstra JBL, Bol E, Zonderland ML, Erkelens DW 1997 Effects of physical training on metabolic control in elderly Type 2 Diabetes Mellitus patients. Clinical Science 93: 127-135 
Ligtenberg PC, Hoekstra JBL, Zonderland ML, Erkelens DW 1995 Physical activity and Diabetes Mellitus. European Journal of Internal Medicine 6: 95-108

Maillet NA, Melkus GD, Spollett G 1996 Using focus groups to characterize the health beliefs and practices of black women with Non-insulin-dependent Diabetes. The Diabetes Educator 22: 39-46

McDougall P 1999 Focus groups: an overview of their use as a research method. Community Practioner 72: 48-49

Mooradian AD, McLaughlin S, Boyer CC, Winter J 1999 Diabetes care for older adults. Diabetes Spectrum 12(2): 70

Norris SL, Englegau MM, Narayan KMV 200 1 Effectiveness of self-management training in Type 2 Diabetes. Diabetes Care 24(3): 561

Oldridge NB, Streiner DL 1990 The health belief model: predicting compliance and dropout in cardiac rehabilitation. Medicine and Science in Sports and Exercise 22(5): 678-683

Oldridge NB, Spencer J 1985 Exercise habits and perceptions before and after graduating or dropout from supervised cardiac exercise rehabilitation. Journal of Cardiac Rehabilitation 5: 313-319
Quatromoni PA, Milbauer M, Posner BM, Carballeira NP, Brunt M, Chipkin SR 1994 Use of focus groups to explore nutrition practices and health beliefs of urban Caribbean Latinos with diabetes. Diabetes Care 17: 869-873

Richter MS 200I The use of focus groups in the development of standards for perinatal education. Unpublished paper: 1-23

Samuel-Hodge CD, Keyserling TC, Headen SW, Jackson, EJ, Skelly AH, Ammerman AS, Ingram AF, Elasy TA 2000 Influences on day-to-day self-management of Type 2 Diabetes among African-American women. Diabetes Care 23(7): 928-933

Skelley AH, Marshall JR, Haughey BP, Davis PJ, Dunford RG 1995 Self-efficacy and confidence in outcomes as determinants of self-care practices in Inner-City, African American women with Non-insulin-dependent diabetes. The Diabetes Educator 21(1): 38-46

Songer TJ 1995 Epidemiology of Type II Diabetes. Pharmaco Economics 8: 1-11

Spirdoso WW, Cronin DL 2001 Exercise dose-response effects on quality of life and independent living in older adults. Medicine and Science in Sports and Medicine 33(6) Suppl: S598-S608
Strauss A, Corbin J 1990 Basics of Qualitative Research. Sage Publications, Newbury Park, CA: $57-73$

Swift CS, Armstrong JE, Beerman KA, Campbell RK, Pond-Smith D 1995 Attitudes and beliefs about exercise among persons with Non-insulin-dependent Diabetes. Diabetes Educator 21:533-540

Van Rooijen AJ, Rheeder P, Eales CJ, Becker P. Black female patients with Type 2 Diabetes Mellitus: Knowledge, Attitudes and Physical Activity. SA Journal of Physiotherapy 2001 Vol 57(3): 20-27

Wannamethee SG, Shaper AG 2001 Physical activity in the prevention of cardiovascular disease: an epidemiological perspective. [Review] Sports Medicine 31: 101-114.

Westaway MS, Viljoen E, Rheeder P, Masemola T 1998 Determining health status and quality of life for Diabetes Mellitus urban black patients and well persons; a pilot study. Draft Report: 1-26.

World Health Organization 1964 Rehabilitation of patients with cardiovascular diseases: report of a WHO Expert Committee. Geneva.

World Health Organization 1999 Ageing and Physical activity: Geneva.

\section{New Millennium Time to think of a change? \\ Quality Locums are looking for quality} personnel in all grades and specialities for work in the UK. Eligibility for a visa or work permit would be an advantage, but even if you are not eligible we would still like to hear from you as we may be able to

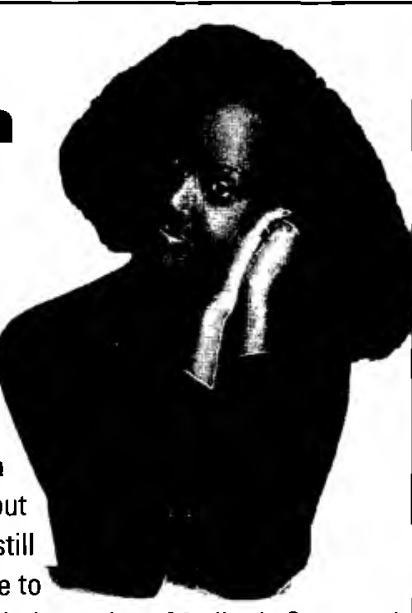
help. Quality Locums are the largest independent Medical, Care and Education Agency in the UK and we have branches in South Africa and Australia. We need Medical Staff of all specialities, Social Workers and Teachers urgently to fill full and part time positions throughout Great Britain and Ireland. We are experts at helping you to take advantage of the opportunities in the UIK. Why not call one of our managers today for an informal discussion.

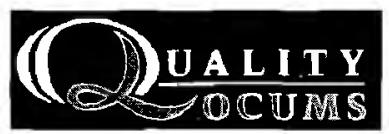

Somja Lewis Quality Locums Cape Town Tel: 0214625357

Fax: 0214625390

Email: Qualitylocums@Worldonline.co.za

Matt Magner Quality Locums Durban

Tel: 0313091471

Email: Wagner@yebo.co.za

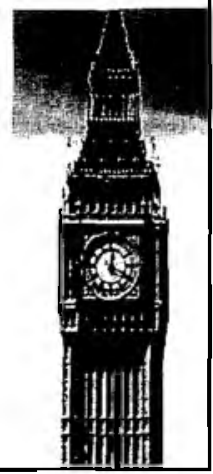

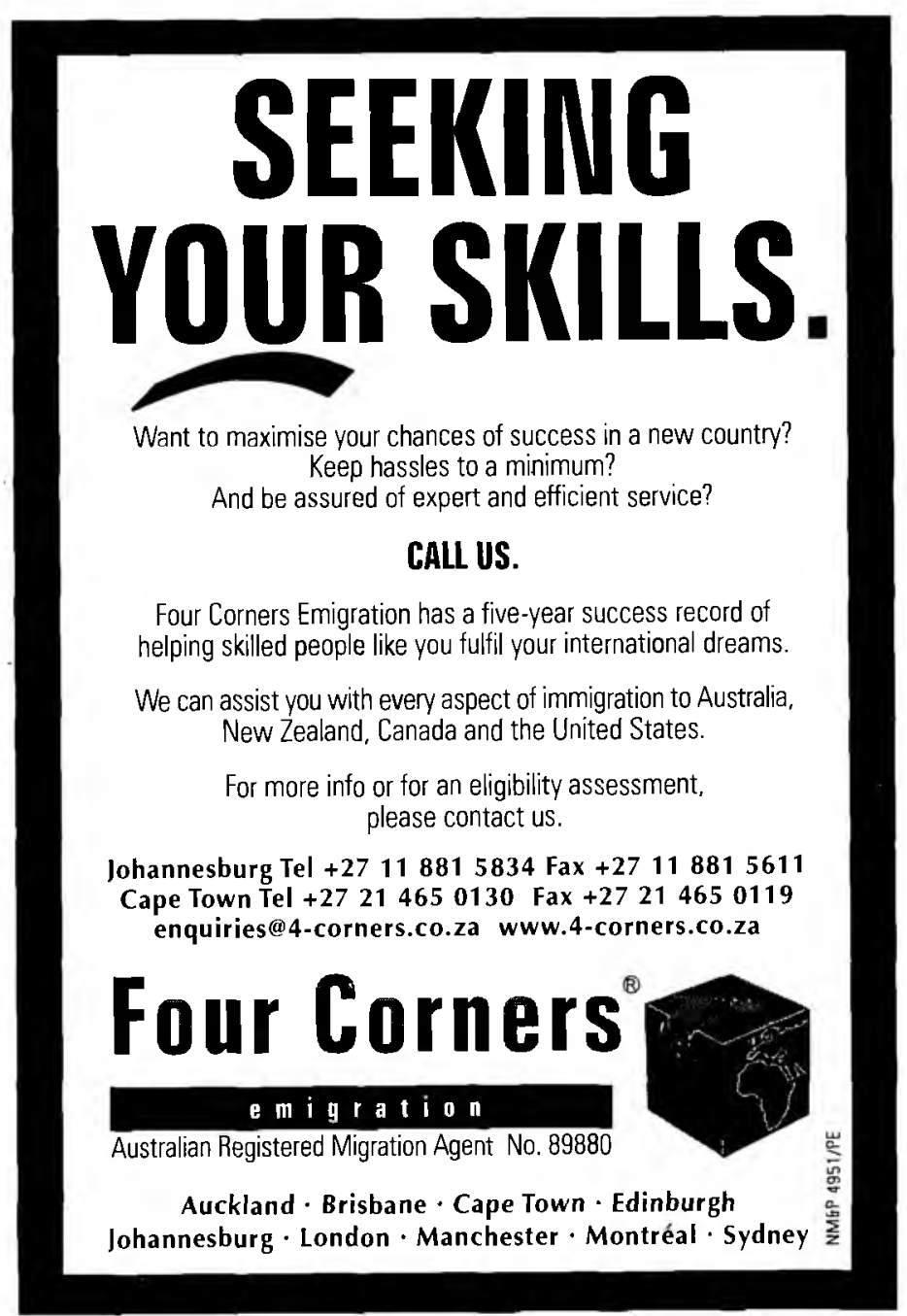

